\title{
Extraction of enzymes from activated sludge
}

\author{
D. Nabarlatz ${ }^{1}$, J. Vondrysova ${ }^{2}$, P. Jenicek ${ }^{2}$, F. Stüber ${ }^{1}$, J. Font ${ }^{1}$, \\ A. Fortuny $^{3}$, A. Fabregat ${ }^{1} \&$ C. Bengoa ${ }^{1}$ \\ ${ }^{1}$ Chemical Engineering Department, Rovira i Virgili University, Spain \\ ${ }^{2}$ Department of Water Technology and Environmental Engineering, \\ Institute of Chemical Technology Prague, Czech Republic \\ ${ }^{3}$ Chemical Engineering Department, Politechnic \\ University of Catalonia, Spain
}

\begin{abstract}
About $60-70 \%$ of the organic matter contained by domestic wastewater is formed by lipids and proteins. The microorganisms that are able to degrade this organic matter produce hydrolytic enzymes that cannot be produced by standard cultivation techniques. The extraction methods have to include detergents or ionic exchange resins to recover qualitatively and quantitatively the enzyme activity. In the present study protease was extracted by using Triton X100 alone or in combination with a cation exchange resin (CER), under stirring, mechanical or ultrasound disintegration at low temperature. It was observed that the temperature of extraction, the agitation velocity, the concentration of the detergent or the cation exchange resin, and the presence/absence of a buffer conditioned the efficiency of the extraction process and the recovery of the enzyme activity. It was also demonstrated that the preservation of the sample (cooled or frozen), and the time of withdrawal (immediately or after one day aeration) changes the activity of the enzyme recovered. The results showed that the best treatment for the recovery of protease is a combination of $60 \mathrm{~g} / \mathrm{g}$ VSS of CER, $0.5 \%$ Triton and $10 \mathrm{mM}$ Tris buffer $\mathrm{pH} 8$, under stirring at $500 \mathrm{rpm}$ during $1 \mathrm{~h}$ at $18^{\circ} \mathrm{C}$. This process allowed to recover 6.48 protease units/g VSS.
\end{abstract}

Keywords: sludge, extraction of enzymes, protease, ultrasound disintegration, mechanical disintegration, stirring, cation exchange resin, Triton X100. 


\section{Introduction}

In the biological treatment plants, the excess activated sludge is becoming a serious issue due to its huge amount that increases annually and the lack of disposal lands. For this reason, the development of new technologies is necessary for reducing the amount of sludge and/or its reusing. The recovery of valuable products from sludge that could be used in the sludge degradation is promising.

Wastewater sludge can be considered as a two phase system formed by a solid network of hydrophilic polymeric materials enclosing water within, making possible to attack enzymatically this complex in order to recover valuable resources, remove toxic materials, recover the water, etc. About $60-70 \%$ of the organic matter contained by domestic wastewater is formed by lipids, proteins and polysaccharides. The microorganisms that are able to degrade this organic matter produces hydrolytic enzymes (i.e. proteases and lipases), and they cannot be grown by standard cultivation techniques. The hydrolysis of the sludge polymers to monomers appears to be the rate-limiting step in the biodegradation process. The enzyme activity in the liquid from activated sludge is almost negligible, so it is still under investigation if the enzymes are immobilized on flocs or attached to the cellular wall by ionic and hydrophobic interactions. The extraction methods have to include detergents or ionic exchange resins that allows to recover the enzymes maintaining them active [1-4].

In the present work some preliminary experiments were carried out testing several disintegration techniques like mechanical disintegration, ultrasound disintegration and stirring for the release of enzymes (protease) from activated sludge. These disintegration techniques were combined with several pre- and post- sludge treatments according to that founded in literature (i.e. cation exchange resin, non ionic detergent, etc).

\section{Materials and methods}

\subsection{Sludge collection and handling}

The sludge samples were collected from the activated sludge tanks of Prague Central Wastewater Treatment Plant (Czech Republic). The samples were taken and transported to the laboratory in $30 \mathrm{~min}$. All the analyses were carried out in the same day, or if it was not possible, they were preserved under aeration at room temperature. The sludge was settled in the fridge to cool it simultaneously and decanted (when possible), and the supernatant eliminated in order to have higher solids concentration in the remaining liquid. The sludge was analysed in order to determine the content in total solids (TS) and volatile suspended solids (VSS) by gravimetry according to the standard methods [5].

\subsection{Extraction of enzymes}

The disintegration of sludge was carried out using three different techniques: Ultrasound Disintegration (UD), Mechanical Disintegration (MD), and Stirring (S). The characteristics for the different equipments are the following: 
-Mechanical disintegration: Disintegrator Ultra - Turrax T25 Basic (purchased from IKA, Germany). Speed: $24000 \mathrm{rpm}$ and $11000 \mathrm{rpm}$. Disintegration time: $1,5,10 \mathrm{~min}$.

-Ultrasonic disintegration: Sonotrode Disintegrator (purchased from ECOSON) - Frequency $20 \mathrm{kHz}$, input power $180 \mathrm{~W}$. Disintegration time: 1, 5, $10 \mathrm{~min}$.

-Stirring: The experiments were carried out using a magnetic stirrer at 500 rpm for $1 \mathrm{~h}$.

The volume of sludge used for the mechanical and ultrasound disintegration test was $200 \mathrm{~mL}$, and for the experiments using stirring was $50 \mathrm{~mL}$ of sludge. The experiments using ultrasound disintegration and stirring were carried out using a water-ice bath for controlling the temperature (for mechanical disintegration it was not possible due to the equipment configuration).

In all the cases the sludge was left in the fridge $1 \mathrm{~h}$ for cooling before the disintegration process. Samples of sludge taken before and after the disintegration process were centrifuged for $10 \mathrm{~min}$ at $13000 \mathrm{rpm}$ prior to the analysis. The supernatant remaining was used as the source of enzyme.

\subsection{Sludge treatments}

During the disintegration experiments, several types of treatments were applied to the sludge according to some previous methods founded in literature [1-4]:

-Washing: $200 \mathrm{~mL}$ of sludge were mixed manually with $200 \mathrm{~mL}$ deionized $\mathrm{H}_{2} \mathrm{O}$. The final mixture was centrifuged and the supernatant discarded. The settled sludge was suspended in $200 \mathrm{~mL}$ of deionized $\mathrm{H}_{2} \mathrm{O}$, and the washed sludge was disintegrated/analysed for enzyme activity.

-Addition of Tris Buffer: For $\mathrm{pH}$ adjustment, $1 \mathrm{M}$ Tris/HCl Buffer $(\mathrm{pH} 8)$ was added to the sludge in order to have a final concentration of $10 \mathrm{mM}$. After that, the sludge was disintegrated/analysed for enzyme activity.

-Addition of Cation Exchange Resin (CER): In the experiments using stirring, a CER (Dowex Marathon Sodium Form, 20-50 mesh, Sigma Aldrich) was added alone or in combination with other treatments in order to have a final concentration of $60 \mathrm{~g}$ CER/g VSS. The samples obtained after extraction were centrifuged, and the supernatant was used for the determination of the enzyme activity.

-Addition of Triton X100: Triton X100 (Sigma Aldrich), is a non-ionic detergent. It was added in two different concentrations $(0.1 \% \mathrm{w} / \mathrm{w}$, and $0.5 \%$ $\mathrm{w} / \mathrm{w}$ ) alone or in combination with other types of treatments. The samples obtained after extraction were centrifuged, and the supernatant was used for the determination of the enzyme activity.

\subsection{Analytical procedures}

The supernatant recovered from the different experiments was analysed to determine the enzyme content. The analytical procedure was taken from Standard Procedures by Sigma Aldrich. The activity of protease was determined using casein as substrate, measuring the concentration of L-tyrosine released by 
spectrophotometry. A $0.65 \%(\mathrm{w} / \mathrm{v})$ casein solution was prepared in $50 \mathrm{mM}$ potassium phosphate buffer $\left(\mathrm{pH} 7.5\right.$ at $\left.37^{\circ} \mathrm{C}\right) .5 \mathrm{~mL}$ of the substrate solution was mixed with $1 \mathrm{~mL}$ of the enzyme solution and incubated during $10 \mathrm{~min}$ at $37^{\circ} \mathrm{C}$. Then $5 \mathrm{~mL}$ of $110 \mathrm{mM}$ trichloroacetic acid was added. After $30 \mathrm{~min}$ of incubation at $37^{\circ} \mathrm{C}$, the reaction mixture was centrifuged at $13000 \mathrm{rpm}$ for 10 $\min$. The clear supernatant $(2 \mathrm{~mL})$ was mixed with $5 \mathrm{~mL}$ of $500 \mathrm{mM} \mathrm{Na}_{2} \mathrm{CO}_{3}$ and $1 \mathrm{~mL}$ of Folin and Ciocalteu's Phenol reagent. This mixture was incubated for 30 min at $37^{\circ} \mathrm{C}$ and finally centrifuged at $13000 \mathrm{rpm}$ for $10 \mathrm{~min}$. The absorbance of this solution was measured at $660 \mathrm{~nm}(1 \mathrm{~cm}$ light path) against a blank. The concentration of L-tyrosine was determined by comparison with a calibration curve. The Unit definition for the enzyme activity consider that one (1) unit of protease will hydrolyse casein to produce colour equivalent to $1.0 \mathrm{mmol}$ of $\mathrm{L}$ tyrosine per minute.

\subsection{Abbreviations}

- 0.1 Triton: $0.1 \% \mathrm{w} / \mathrm{w}$ Triton X100

- 0.5 Triton: $0.5 \% \mathrm{w} / \mathrm{w}$ Triton X100

- 5: $5 \mathrm{~min}$

- 11: $11000 \mathrm{rpm}$

- 24: $24000 \mathrm{rpm}$

- CER: Cation Exchange Resin (60 g/g VSS)

- MD: Mechanical Disintegration

- S: Stirring

- Tris: $10 \mathrm{mM}$ Tris buffer $\mathrm{pH} 8$

- TS: Total Solids

- UD: Ultrasound Disintegration

- VSS: Volatile Suspended Solids

\section{Results}

The content in Total Solids (TS) and Volatile Suspended Solids (VSS) varied between 8.6-14.3 g/L for TS and 6.0-10.3 g/L for VSS respectively, mainly due to the variation in the wastewater plant in the different dates of collection, and also to that the solids were settled and concentrated in order to have a higher solids content.

Some preliminary experiments were carried out in order to evaluate the influence of a washing step prior to the extraction step. It was found that part of the enzyme is present in the liquid, and that is lost during washing (results not shown). For this reason, for the next experiments the sludge will be just decanted and the supernatant eliminated, in order to have the original liquid with a higher amount of solids.

Concerning the handling of the sludge, the collection from the plant and the disintegration experiments were carried out in the same day (or preserved under aeration at room temperature until the next day if it was not possible). It seems that the best option is to process the sludge as soon as possible to eliminate 
possible damage of the microorganisms and enzymes. Also it was observed that the enzyme samples (supernatant) lost some activity when they were preserved frozen, so finally all of them were analysed in the same day, or preserved in the fridge at $4^{\circ} \mathrm{C}$ and analysed in the next day.

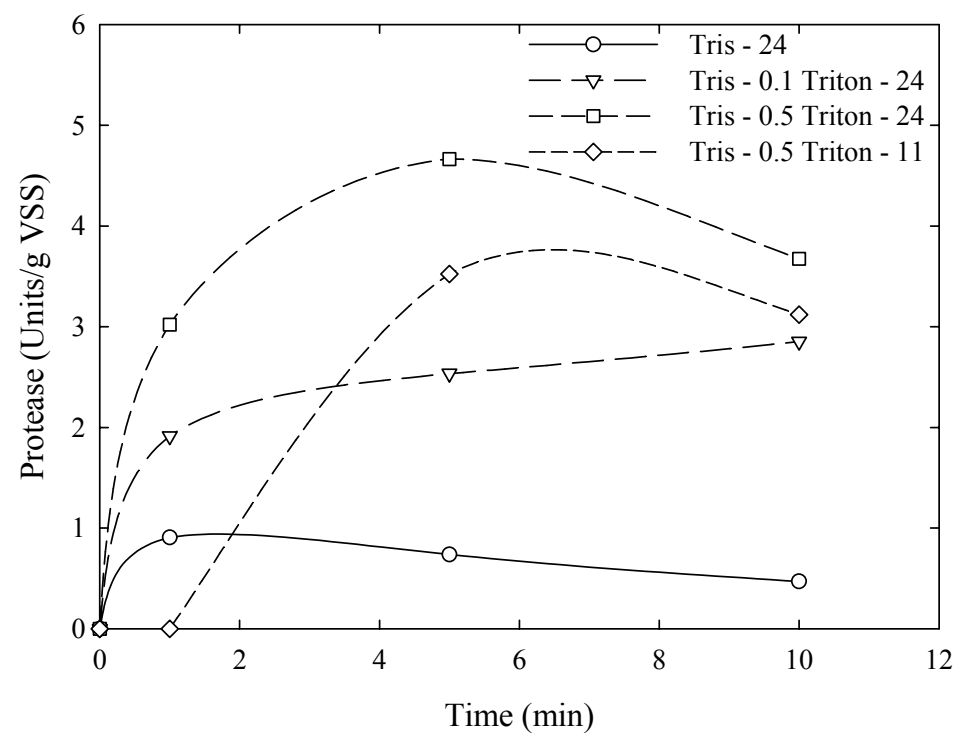

Figure 1: Extraction of protease by mechanical disintegration of biological sludge (lines only indicate trends).

The results for the extraction of protease from sludge by using mechanical disintegration are shown in Figure 1. As can be observed, the influence of the type of treatment and also the influence of the time during the disintegration was evaluated. There is a significant difference between the different types of treatment applied. It seems that the buffer alone has no significant effect on the protease extraction, and that the increase in the concentration of Triton and the velocity of extraction have a remarkable effect on the enzyme extraction.

The highest protease activity was around 4.6 units of enzyme/g VSS for $5 \mathrm{~min}$ of mechanical treatment, using $10 \mathrm{mM}$ Tris buffer $\mathrm{pH} 8$ combined with $0.5 \%$ $\mathrm{w} / \mathrm{w}$ Triton at $24000 \mathrm{rpm}$. Using $10 \mathrm{~min}$ of disintegration, the activity decreases, may be because the effect of the high temperature reached (around $50^{\circ} \mathrm{C}$ ) (see Figure 2). In order to observe the influence of the velocity during the mechanical disintegration, the experiments were carried out under the same conditions at 24000 and $11000 \mathrm{rpm}$. It can be observed that the decrease in the velocity leads to a decrease in the protease activity and also a decrease in temperature.

As can be observed in Figure 2, the temperature of the extraction mixture is affected almost linearly with the time of processing, reaching almost $50^{\circ} \mathrm{C}$ for 10 min of treatment at $24000 \mathrm{rpm}$. It was observed that this temperature is strongly dependent on the velocity of extraction, because for the same time of extraction 
the final temperature is around $20^{\circ} \mathrm{C}$ at $11000 \mathrm{rpm}$. During the mechanical disintegration it was not possible to have a water-ice bath due to the equipment configuration, being not possible to control the temperature. This increase in the temperature may partially affect the enzyme activity, due to that the optimal temperature for protease is around $37-40^{\circ} \mathrm{C}$, and this can explain the decrease in the enzyme activity for times longer than $5 \mathrm{~min}$.

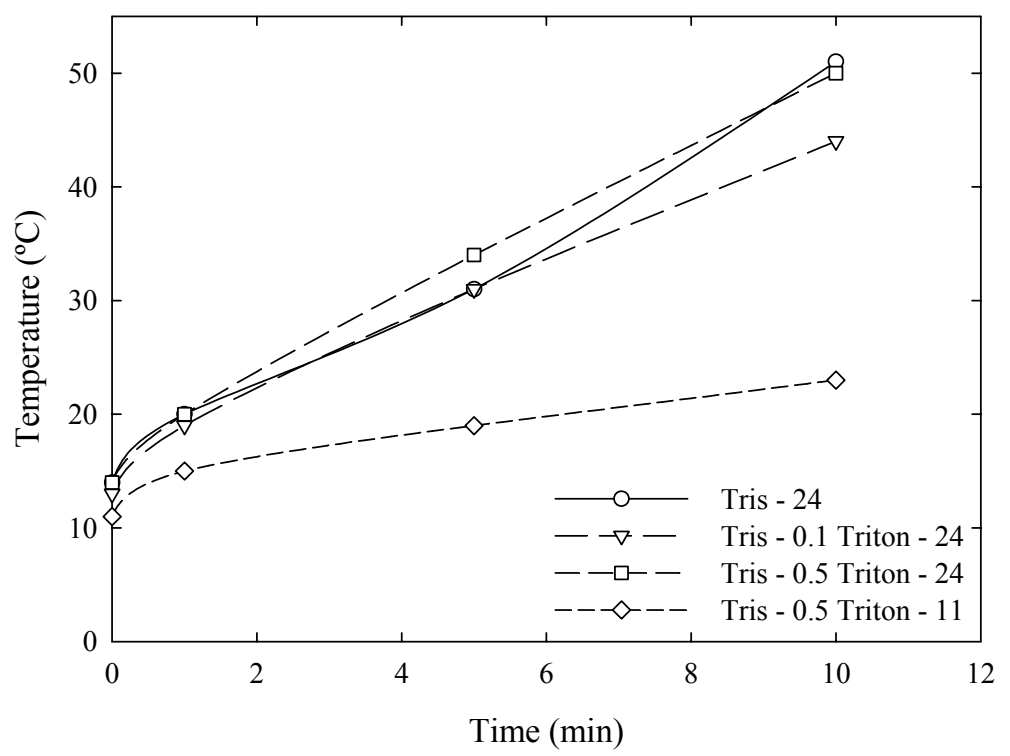

Figure 2: Temperature variation during the mechanical disintegration of biological sludge (lines only indicate trends).

Figure 3 shows the results for the extraction of protease by ultrasound disintegration using different treatments. The behaviour is different than in the mechanical disintegration, because in $5 \mathrm{~min}$ of treatment is reached the maximum of enzyme activity and it is maintained in time. Again the buffer alone has no significant effect on the protease extraction, but the increase in the concentration of Triton seems to be responsible for the release of the enzyme. It can be observed that the treatment of sludge with $10 \mathrm{mM}$ Tris buffer $\mathrm{pH} 8$ combined with $0.5 \%$ Triton yields the higher protease activity (around 4.5 Units of enzyme/g VSS) in 5 min of sonication. Using just $0.5 \%$ Triton during 5 min of disintegration, yields also around 5 Units of enzyme/g VSS, which confirms that the buffer has no significant effect on the protease extraction. The increase in temperature is not so marked as in the mechanical disintegration (see Figure 4), being the final temperature near to $30^{\circ} \mathrm{C}$ for $10 \mathrm{~min}$ of disintegration. This is in correspondence with the lower friction caused by the treatment, and also because it was possible to use a water-ice bath during the process. 


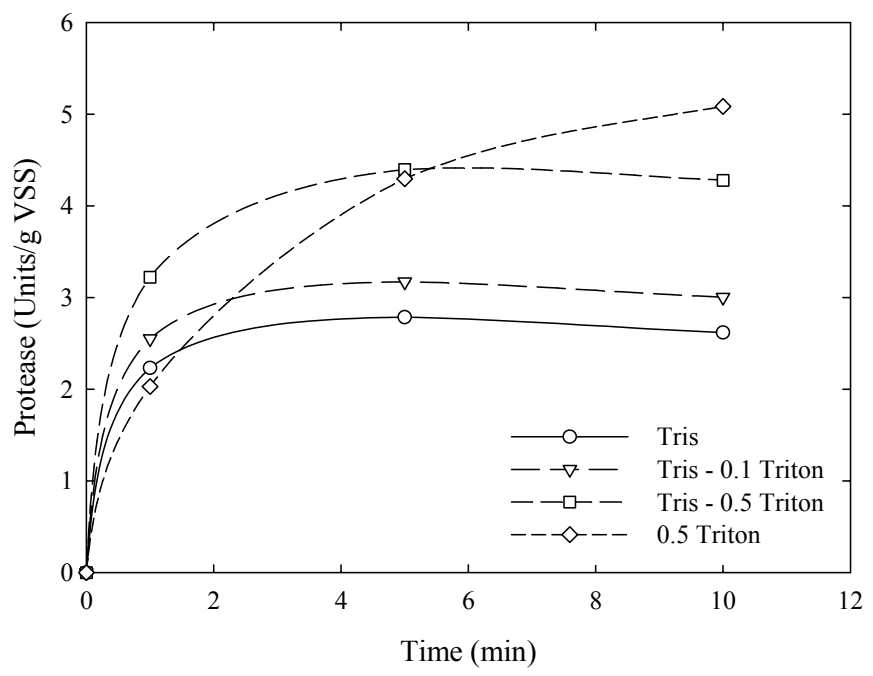

Figure 3: Extraction of protease by ultrasound disintegration of biological sludge (lines only indicate trends).

Figure 5 shows the results for the experiments using stirring at $500 \mathrm{rpm}$ during 1 hour, and compare them with the results using ultrasound treatment. When the concentration of Triton is increased from $0.1 \%$ to $0.5 \%$ the enzyme activity increases from 2.4 to 3.2 units enzyme/g VSS. These results are lower than those obtained using ultrasound treatment.

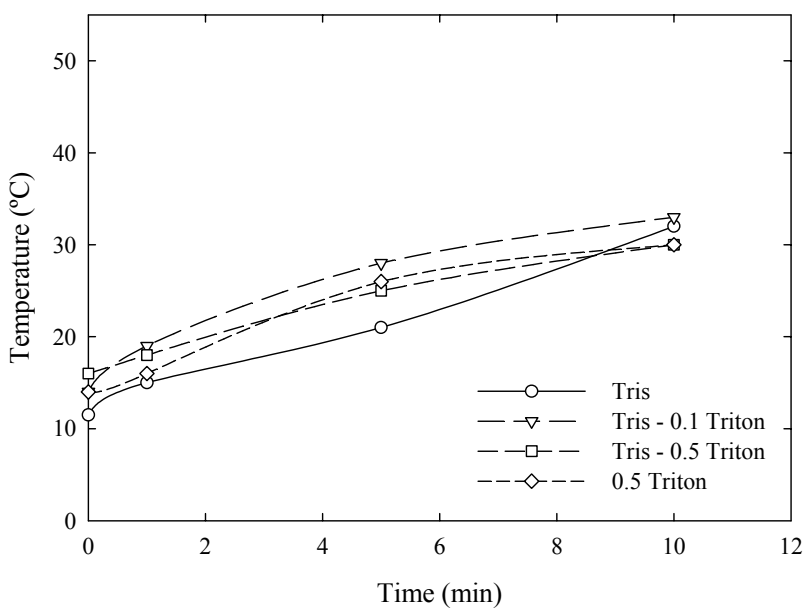

Figure 4: Temperature variation during the ultrasound disintegration of biological sludge (lines only indicate trends). 


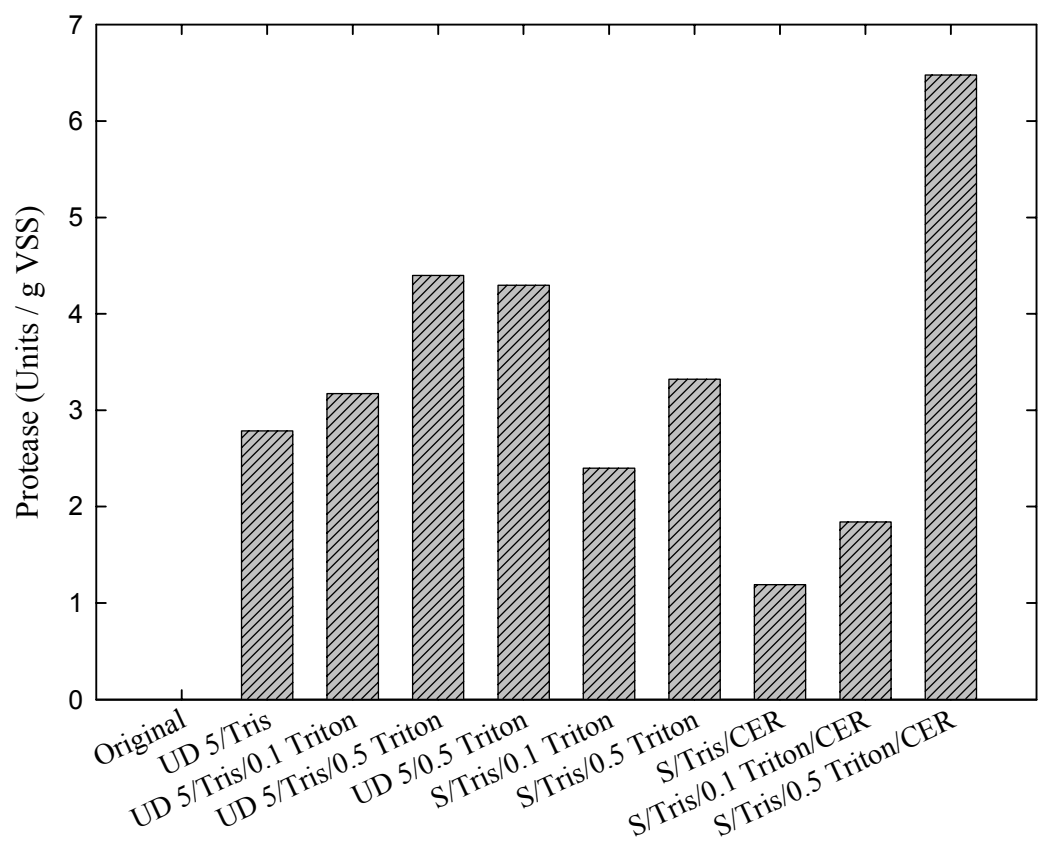

Figure 5: Extraction of protease from biological sludge by stirring at 500 rpm during $1 \mathrm{~h}$, and comparison with the results obtained using ultrasound disintegration.

But, as can be observed, the treatment with $10 \mathrm{mM}$ Tris $+0.5 \%$ Triton $+60 \mathrm{~g}$ CER/g VSS yields around 6.5 Units of enzyme/g VSS, which is higher than the best results obtained using ultrasound or mechanical disintegration. It seems that a combination of Triton together with a cation exchange resin enhances the enzyme extraction. Another procedure which has to be evaluated in future is to extract the enzyme using ultrasound disintegration with Triton followed by stirring with a cation exchange resin, which may be will increase the enzyme activity recovered.

\section{Conclusions}

The extraction of protease from activated sludge was carried out by ultrasound disintegration, mechanical disintegration and stirring. The results showed that the maximal activity recovered using the mechanical disintegration was around 4.6 units of enzyme/g VSS for 5 min of treatment, using $10 \mathrm{mM}$ Tris buffer $\mathrm{pH} 8$ combined with $0.5 \% \mathrm{w} / \mathrm{w}$ Triton at $24000 \mathrm{rpm}$. The extraction is affected by the rotation velocity and the temperature reached. For the ultrasound disintegration, the maximal activity recovered was almost the same, 4.5 units of enzyme/g VSS for $5 \mathrm{~min}$ of disintegration, using the same concentration of buffer and detergent as before. When these results are compared with that obtained using stirring, it 
was found that the extraction of protease using $10 \mathrm{mM}$ Tris buffer $\mathrm{pH} 8+0.5 \%$ $\mathrm{w} / \mathrm{w}$ Triton $+60 \mathrm{~g} \mathrm{CER/g} \mathrm{VSS} \mathrm{yields} \mathrm{around} 6.5$ Units of enzyme/g VSS. It seems that this combination of Triton with CER is the best option for the extraction of protease. In future disintegration experiments, different concentrations of detergent combined with simultaneous or subsequent treatments using CER will be tested in order to optimise the protease recovery.

\section{Acknowledgement}

The financial support for this research was provided by the European Union Research Sixth Framework Programme, project REMOVALS, FP6-018525.

\section{References}

[1] Cadoret, A., Conrad, A. \& Block, J.C. Availability of low and high molecular weight substrates to extracellular enzymes in whole and dispersed activated sludges. Enzyme and Microbial Technology, 31, pp. 179-186, 2002.

[2] Gessesse, A., Dueholm, T., Petersen, S. \& Nielsen, P. Lipase and protease extraction from activated sludge. Water Research, 37, pp. 3652-3657, 2003.

[3] Frolund, B., Palmgren, R., Keiding, K. \& Nielsen, P. Extraction of extracellular polymers from activated sludge using a cation exchange resin. Water Research, 30, pp. 1749 - 1758, 1996.

[4] Jung, J., Xing, X. \& Matsumoto, K. Recoverability of protease released from disrupted excess sludge and its potential application to enhanced hydrolysis of proteins in wastewater. Biochemical Engineering Journal, 10, pp. 67-72, 2002.

[5] American Water Association, Standard Methods for the Examination of Water and Wastewater, Washington American Public Health Association, Washington, 1999. 